\title{
The reduction of fringing-effect power loss in gapped ferrite inductors by changing the resistance and diameter of windings
}

\author{
by R. Kasikowski*, ${ }^{* *}$, B. Więcek*
}

*Łódź University of Technology, Institute of Electronics, 211/215 Wólczańska str, 90-924 Łódź,Poland, wiecek@p.lodz.pl

** Stadium Stontronics Ltd, Research \& Development Centre, Norwich Research Park, NR4 7UG, Norwich, United Kingdom, rafal.kasikowski@stadium.co.uk

\section{Abstract}

This article examines power loss and temperature distribution in the windings of gapped ferrite inductors exposed to a high fringing magnetic field at an air gap. The fringing magnetic field generates eddy-current losses in adjacent conductors, impacting the efficiency of power conversion. This extra power loss manifests itself in the form of so-called hotspots, and can be analysed by IR thermography. The presented research shows how a change in the cross-sectional area and/or resistivity of the wires near the air gap can decrease fringing-effect losses.

\section{Introduction}

Gapped ferrite core magnetics find widespread applications in power conversion. The presence of an air gap is required in order to prevent the core from reaching its saturation point, losing its magnetic properties and turning, technically, into an air core. Designs in which conversion of power requires an air gap of a substantial size in the magnetic path of the component frequently exhibit impaired performance due to the fringing effect phenomenon at the air gap [1]. When approaching the air gap, the magnetic field lines, which until that point are entirely enclosed by the core, tend to fringe out beyond the cross-sectional area of the core and enter the surrounding medium, usually copper winding (see Fig. 1)

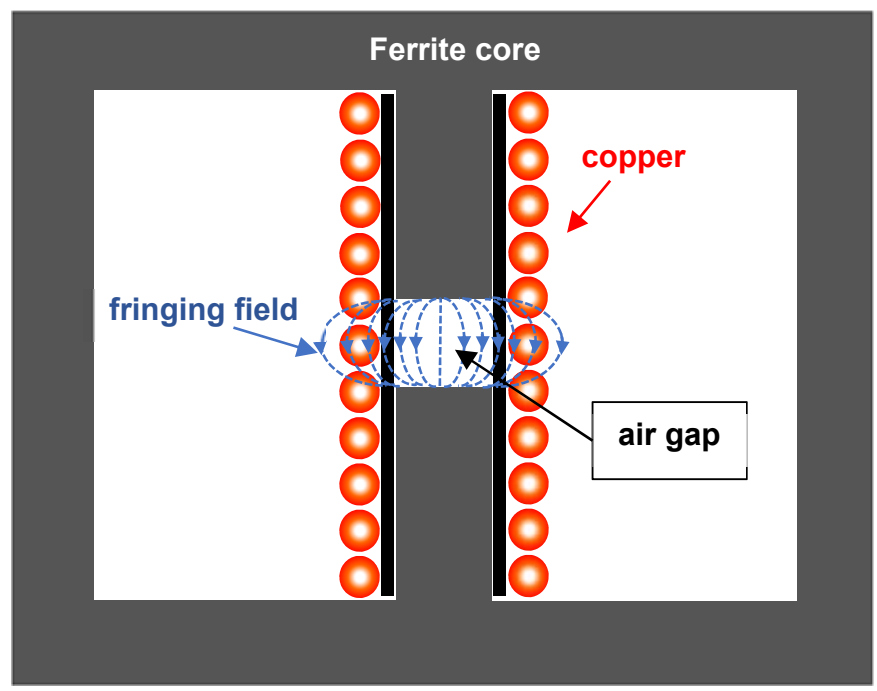

Fig. 1. Fringing magnetic field near an air gap.

The leaked magnetic flux crosses windings, inducing voltage within conducting material. The induced voltage generates eddy currents that tend to counteract the useful current, and, as a result, the effective area of the conductor is reduced, whereas both the so-called $A C$ resistance $\left(R_{A C}\right)$ and the power loss are increased. The phenomenon manifests itself in the form of localized heating (hotspots - see Fig. 2) and extra power loss [2, 3]. 


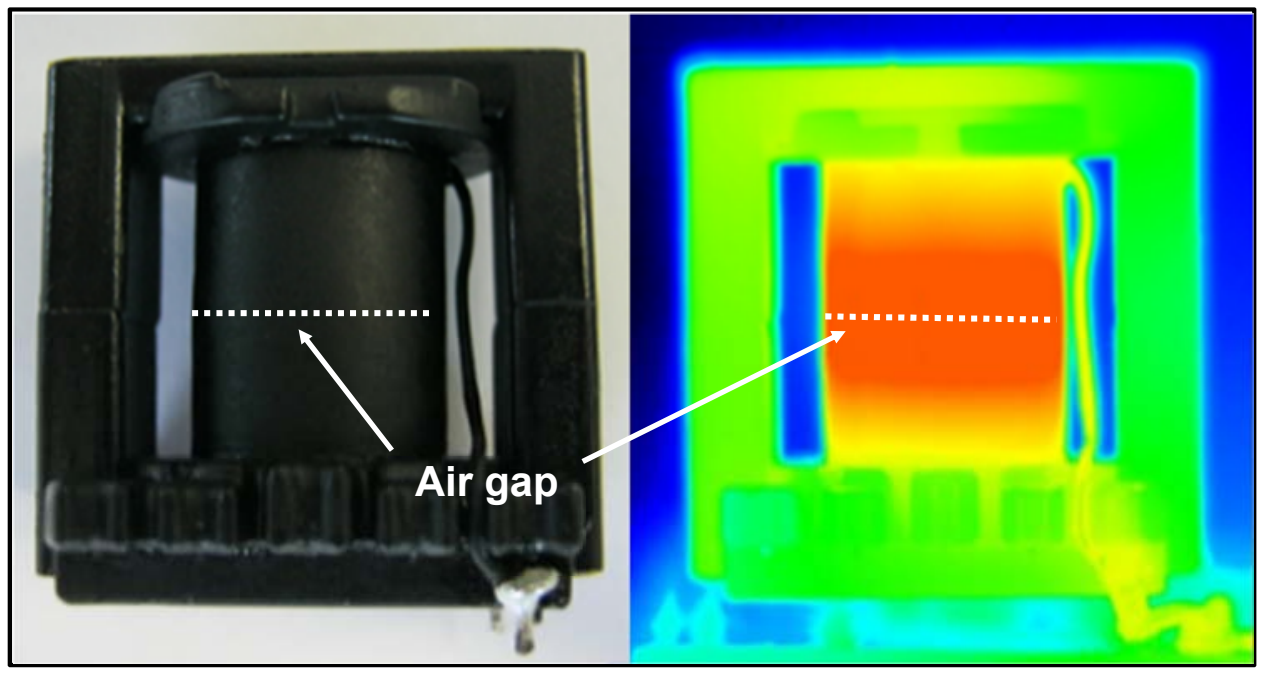

Fig. 2. Elevated temperature (hotspot) due to the fringing effect in windings around an air gap in a centregapped ferrite inductor.

Besides the fringing effect, there are two other distinct mechanisms behind the induction of eddy currents in copper wires. At low frequencies, current density in a conductor is nearly homogenous, whereas at high frequencies, a changing magnetic field resulting from current flow drives eddy currents within the conductor. These currents are the root cause of the reduction in the net current density in the centre of the conductor and the increase in the current flowing near the surface (see Fig. 3). This specific eddy-current mechanism is referred to as the skin effect, and, like the fringing effect, decreases the effective area of the conductor and adds to power loss. The distance from the surface to the point within the conductor where the current density is $1 / \mathrm{e}$ of the surface density is known as the skin depth $\delta$ [4]. Eq. (1).

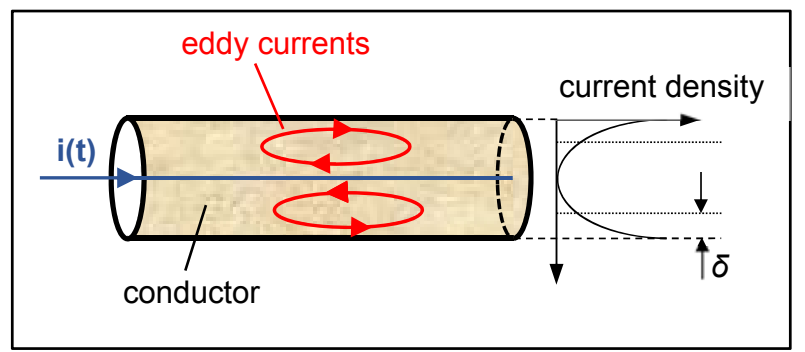

Fig. 3. Current density distribution in a conductor carrying a high frequency AC-current.

$$
\delta=\sqrt{\frac{\rho}{\pi \cdot \mu \cdot f}}
$$

where $\mu$ and $f$ denote the permeability of the conductor and frequency, respectively.

If an AC-current-carrying conductor is brought into the immediate vicinity of another AC-current-carrying conductor, the resulting magnetic field alters the distribution of current density within both conductors. This phenomenon is known as the proximity effect, Fig. 4. All the AC-resistance-increasing mechanisms are intensified at high frequencies, and increased power loss occurs, Eq. (2).

$$
P_{A C}=R_{A C} \cdot I_{R M S}^{2}>P_{D C}=R_{D C} \cdot I_{R M S}^{2}
$$




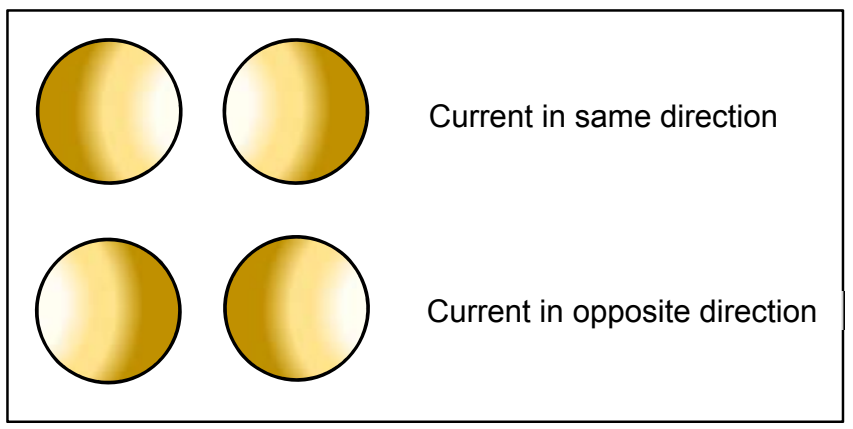

Fig. 4. Current density distribution in neighbouring conductors carrying a high-frequency AC current [5].

As shown in [6], centre-gapped ferrite core inductors display a distinctive pattern in temperature distribution in windings if measured along the gapped middle column, Fig. 5. The maximum temperature and the power-loss density in the section of the coil located directly above the air gap, where the fringing-effect component is the greatest, is considerably higher than in the areas away from the air gap.

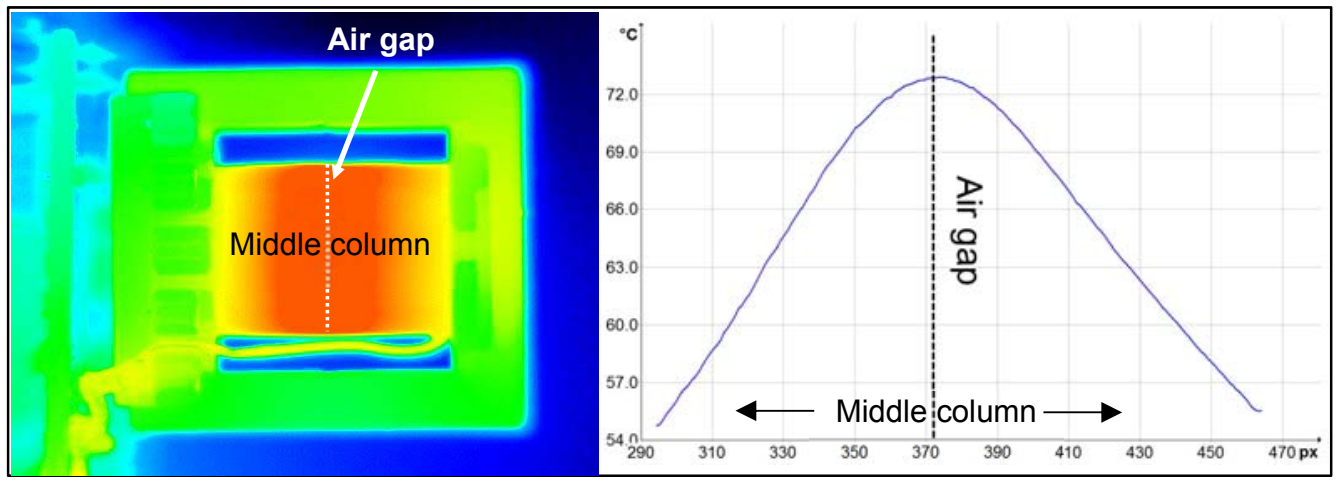

Fig. 5. Temperature distribution along a centre-gapped middle column.

As the efficiency of power conversion is often the best determinant of a converter's performance, new designs frequently feature some method of reducing the fringing-effect loss: shielding, spacing windings away from the air gap, coils constructed out of Litz wire, etc. As shown herein, the power loss associated with the fringing-effect phenomenon can be lessened by decreasing the diameter of a section of the wire positioned over an air gap or/and by increasing its resistance via the change in the material used.

\section{Measurement setup}

To demonstrate modulations in the fringing-effect loss inside the winding as described above, the ferrite inductor in Fig. 2 was used. The air gap of $2.5 \mathrm{~mm}$ was positioned symmetrically in the middle of the centre column. The component was constructed using ER28/14/11 3C90 ferrite cores [7] and mounted, prior to the measurements, on the back of the 36 W forward converter (Fig. 6), so as to eliminate the influence of any heat-radiating top-mounted components. The core was combined with a 20 -turn coil of $0.71 \mathrm{~mm}$ diameter, wound on a phenolic bobbin, to build an inductor of about 31.00 $\mu \mathrm{H}$. The converter itself was set to run at a frequency of about $63.4 \mathrm{kHz}$ with the output parameters of $12 \mathrm{~V}$ and $3 \mathrm{~A}$, and the input voltage of $24 \mathrm{~V}$. The measured power loss in the converter in this setup was used as a reference point for further measurements. Subsequently, the section of the winding (about $5 \mathrm{~mm}$ along the middle column) located directly over the air gap was modulated in terms of the wire's diameter and resistance to register changes in the converter's efficiency and temperature distribution in the coil. The remaining parameters of the converter remained unchanged throughout the experiment and the tests were carried out in a constant external ambient. The inductance of the constructed ferrite chokes was measured using PHILIPS PM 6304 programmable automatic RCL meter and the total power loss in the converter was ascertained by measuring voltages and currents at the input and output of the converter. Paragraph 3 of this paper gives the method applied to measure the total DC-resistance of the constructed coils. The results of the measurements are expressed in the SI original units. 


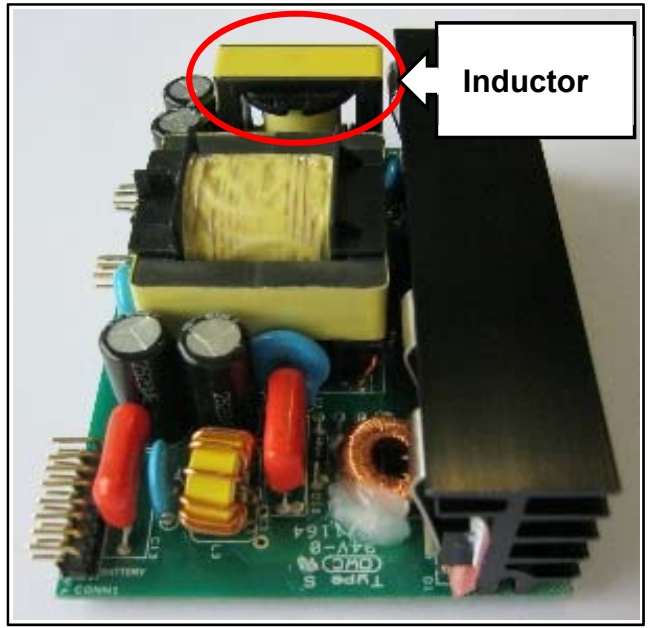

Fig. 6. Constructed forward converter.

\section{Results and Analysis}

Since it is a function of many variables, the fringing effect is a complex phenomenon. The fringing magnetic flux strength, the area impacted by it and the power losses associated with the effect depend on of the size of the air gap, the cross-sectional area of the core, the magnetic flux density swing, the distance from the gap to the windings, the geometry of the windings, the operating frequency, and so forth. Therefore, it was of paramount importance in the experiment carried out to keep the parameters of the constructed inductor unchanged, particularly its inductance and geometry, so that the modifications in the section of the winding above the air gap had no bearing on the operating conditions of the converter and the fringing flux itself, but on the power loss in the winding alone.

The starting point for the experiment was the inductor with the parameters given in Table 1.

Table 1. Properties of the first constructed inductor.

\begin{tabular}{|c|c|c|c|}
\hline \multicolumn{4}{|c|}{$\mathbf{1}^{\text {st }}$ Output Inductor - Properties } \\
\hline Wire diameter $\mathbf{~ m m}$ & Wire material & $\begin{array}{c}\text { Total DC } \\
\text { Resistance } \mathbf{\Omega}\end{array}$ & $\begin{array}{c}\text { Inductance } \\
\mathbf{H}\end{array}$ \\
\hline 0.71 & $\mathrm{Cu}$ & 0.041621 & 0.00003054 \\
\hline
\end{tabular}

The converter was run with the output current set to $3 \mathrm{~A}$ until the temperatures of its all components settled at their maximum values, at which point the power loss in the converter was measured and the thermal image presented in Fig. 7 was taken with an IR camera.

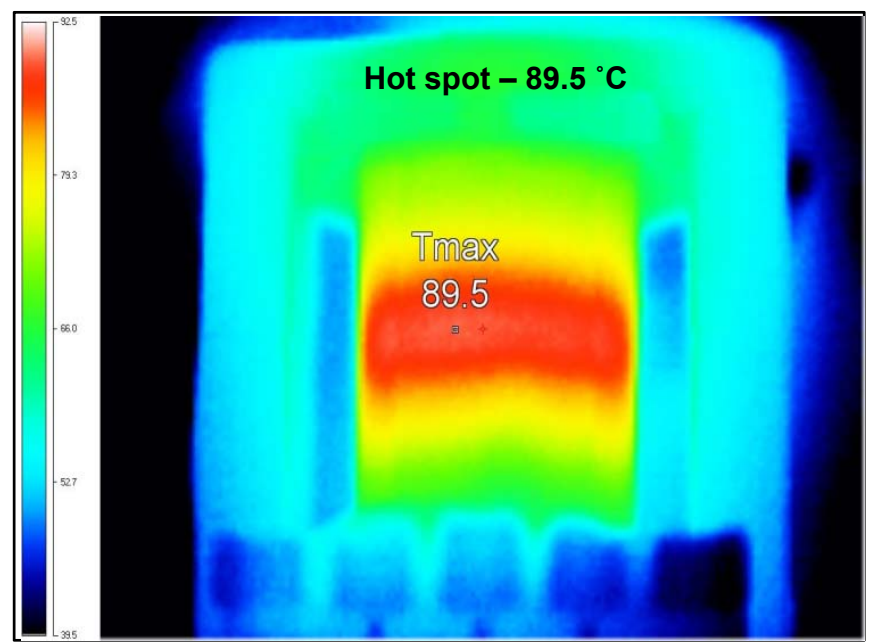

Fig. 7. Thermal image for the inductor with $0.71 \mathrm{~mm}$ diameter winding. 
The total power loss ascertained for the constructed forward converter with the copper coil of $0.71 \mathrm{~mm}$ diameter and DC-resistance of $0.041621 \Omega$ was:

$$
\mathrm{P}_{0.71}=10.29886 \mathrm{~W}
$$

The DC-resistance of $0.041621 \Omega$ corresponded to the $0.71 \mathrm{~mm}$ diameter copper wire with a length of about 0.98 $\mathrm{m}$ as given by the following equation, Eq. 3 :

$$
R_{D C}=\frac{l \cdot \rho_{C u}}{\pi \cdot\left(\frac{D}{2}\right)^{2}}
$$

where: $l$ - the length of the wire, $\rho_{C u}$ - the resistivity of copper $\approx 1.68 \times 10^{-8} \Omega \mathrm{m}, \mathrm{D}-$ the diameter of the wire.

To ensure that the calculated values closely matched the actual resistance of the coils constructed for the experiment, a DC-current of $1 \mathrm{~A}$ was forced through the wire, voltage was measured between the ends of the coils, and Ohm's law was applied. The computed values were analogous to the results of the measurements for each of the constructed coils.

Subsequently, the winding of the inductor was removed and replaced with a winding consisting of two different wire diameters: $0.71 \mathrm{~mm}$ and $0.6 \mathrm{~mm}$. The latter formed the middle section of the winding located directly over the air gap and exposed to the strongest fringing flux. This operation increased the total DC-resistance of the coil to $0.046231 \Omega$ (see Table 2). Again, the converter was run with the output current set to $3 \mathrm{~A}$ until the temperatures of all its components settled at their maximum values before the measurements of power loss and the thermal image of the inductor, Fig. 8, were taken.

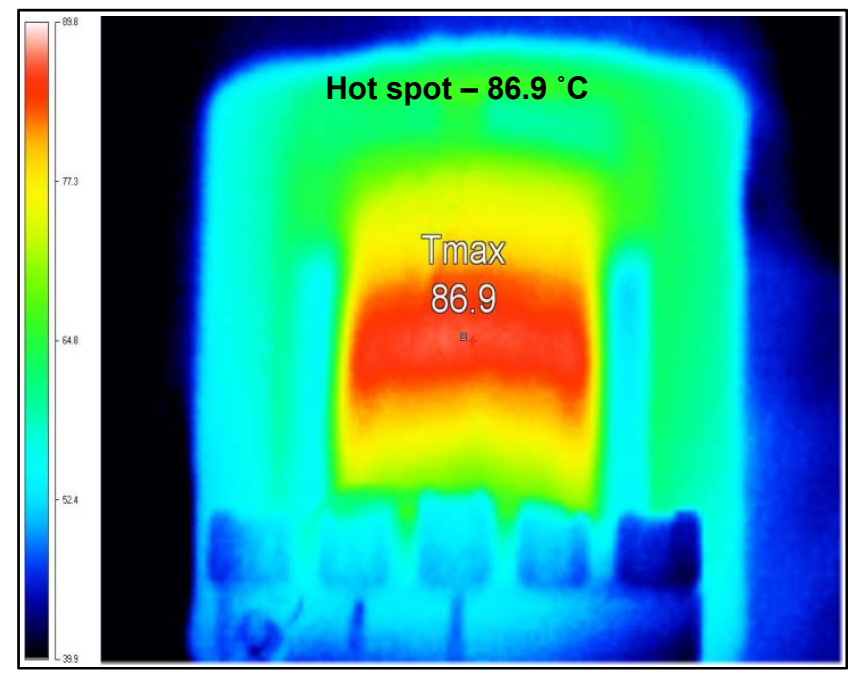

Fig. 8. Thermal image for the inductor with $0.71 \mathrm{~mm} / 0.6 \mathrm{~mm} / 0.71 \mathrm{~mm}$ diameter winding.

Table 2. Properties of the second constructed inductor.

\begin{tabular}{|c|c|c|c|}
\hline \multicolumn{4}{|c|}{$\mathbf{2}^{\text {nd }}$ Output Inductor - Properties } \\
\hline Wire diameter $\mathbf{~ m m}$ & Wire material & $\begin{array}{c}\text { Total DC } \\
\text { Resistance } \Omega\end{array}$ & $\begin{array}{c}\text { Inductance } \\
\mathbf{H}\end{array}$ \\
\hline $0.71 / 0.6 / 0.71$ & $\mathrm{Cu}$ & 0.046231 & 0.00003015 \\
\hline
\end{tabular}

The total power loss measured for the constructed forward converter with the copper coil of $0.71 \mathrm{~mm} / 0.6 \mathrm{~mm} / 0.71$ mm diameter and DC-resistance of $0.046231 \Omega$ was:

$$
\mathrm{P}_{0.71 / 0.6 / 0.71}=10.13164 \mathrm{~W}
$$

One can notice that the total power dissipated dropped by $0.16722 \mathrm{~W}$, which, at first, may seem counterintuitive, since a reduction in diameter generally leads to an increase in resistance and power loss according to Eq. 2. However, the increased resistance of the coil turns placed around the air gap somewhat diminished the eddy currents induced by the fringing field, hence the measured rise in the converter's efficiency. The increased power dissipation caused by the output current of $3 \mathrm{~A}$ was counteracted by the decreased fringing-effect power loss. This can also be observed in the presented thermal images where the maximum temperature for the second inductor was measurably lower. 
Analogous measurements were conducted for a series of inductors with a modified (in terms of wire diameter) central section of the winding, Table 3 .

Table 3. Properties of constructed inductors and corresponding change in total power loss.

\begin{tabular}{|c|c|c|c|c|c|c|}
\hline \multicolumn{4}{|c|}{ Output Inductor - Properties } & \multicolumn{2}{c|}{ Change in Total Power Loss } \\
\hline No. & $\begin{array}{c}\text { Wire diameter } \\
\mathbf{m m}\end{array}$ & Wire material & $\begin{array}{c}\text { Total DC } \\
\text { Resistance } \mathbf{\Omega}\end{array}$ & $\begin{array}{c}\text { Inductance } \\
\mathbf{H}\end{array}$ & $\begin{array}{c}\text { Power Loss } \\
\mathbf{W}\end{array}$ & $\begin{array}{c}\text { Change in } \\
\text { Dissipation W }\end{array}$ \\
\hline 1 & 0.71 & $\mathrm{Cu}$ & 0.041621 & 0.00003054 & 10.29886 & - \\
\hline 2 & $0.71 / 0.6 / 0.71$ & $\mathrm{Cu}$ & 0.046231 & 0.00003015 & 10.13164 & -0.16722 \\
\hline 3 & $0.71 / 0.5 / 0.71$ & $\mathrm{Cu}$ & 0.054278 & 0.00003119 & 10.08973 & -0.20913 \\
\hline 4 & 0.5 & $\mathrm{Cu}$ & 0.082721 & 0.00003064 & 10.38887 & +0.09001 \\
\hline 5 & $0.71 / 0.45 / 0.71$ & $\mathrm{Cu}$ & 0.061492 & 0.00003100 & 10.14028 & -0.15858 \\
\hline 6 & $0.71 / 0.375 / 0.71$ & $\mathrm{Cu}$ & 0.078223 & 0.00003100 & 10.47143 & +0.17257 \\
\hline
\end{tabular}

As expected, the gain in the converter's efficiency as a function of the diameter of the coil's middle section exhibits a certain optimum for a given output current, which happens to be for a coil configuration of $0.71 \mathrm{~mm} / 0.5 \mathrm{~mm} / 0.71 \mathrm{~mm}$, though its DC-resistance is significantly higher than the reference inductor's DC-resistance. For the last inductor in Table 3 , a reduction in dissipation brought about by a decrease in the magnitude of eddy currents induced by the fringing field at the air gap is countered by increased losses caused by the flow of the useful output current.

The magnitude of eddy currents generated by the fringing field at the air gap can also be diminished by a change in the material of the wire in the section of the winding located directly over the air gap. By selecting conductive materials with a higher resistivity than pure copper, coils were de facto constructed with increased resistance to current flow. The following copper-nickel alloys were used in the research, Table 4:

Table 4. Copper-nickel alloys used in experiment.

\begin{tabular}{|c|c|c|}
\hline Wire material & $\begin{array}{c}\text { Wire diameter } \\
\mathbf{~ m m}\end{array}$ & Resistivity $\mathbf{\Omega m}$ \\
\hline $\mathrm{CuNi1}$ & 0.71 & $2.8 \times 10^{-8}$ \\
\hline $\mathrm{CuNi2}$ & 0.71 & $5 \times 10^{-8}$ \\
\hline
\end{tabular}

Once more the same middle section of the winding was replaced, firstly with CuNi1 and then with CuNi2 wire, and the converter was kept running, for both cases, until it reached the maximum steady temperature, at which point the total power losses were ascertained, Table 5.

Table 5. Properties of constructed inductors and corresponding change in total power loss.

\begin{tabular}{|c|c|c|c|c|c|}
\hline \multicolumn{4}{|c|}{ Output Inductor - Properties } & \multicolumn{2}{c|}{ Change in Total Power Loss } \\
\hline Wire diameter $\mathbf{m m}$ & Wire material & $\begin{array}{c}\text { Total DC } \\
\text { Resistance } \Omega\end{array}$ & $\begin{array}{c}\text { Inductance } \\
\mathbf{H}\end{array}$ & $\begin{array}{c}\text { Power Loss } \\
\text { W }\end{array}$ & $\begin{array}{c}\text { Change in } \\
\text { Dissipation W }\end{array}$ \\
\hline 0.71 & $\mathrm{Cu}$ & 0.041621 & 0.00003054 & 10.29886 & - \\
\hline 0.71 & $\mathrm{Cu} / \mathrm{CuNi} 1 / \mathrm{Cu}$ & 0.050184 & 0.00003050 & 10.20272 & -0.09614 \\
\hline 0.71 & $\mathrm{Cu} / \mathrm{CuNi2/Cu}$ & 0.064977 & 0.00003053 & 10.1594 & -0.13946 \\
\hline
\end{tabular}

One can infer from the table above that, like the reduction in diameter, the increase in the conductor's resistivity in areas exposed to strong fringing magnetic fields limited the induced eddy currents. As long as extra power dissipation due to the output current flow through the higher value of the coil's total DC-resistance was lower than the decrease in fringing-effect power loss, an improvement in the efficiency of power conversion was observed.

It has to be stressed that the presented method of reducing fringing-effect power loss in gapped ferrite inductors by changing the resistance and/or diameter of windings is only valid for relatively low output currents and air gaps of rather substantial dimensions where the amount of fringing flux encompassing windings is high. Were the useful current set to a higher value than the $3 \mathrm{~A}$ used in the experiment, the gain in the converter's efficiency would be diminished, quickly becoming negligible, and at a certain point the change in efficiency would undergo a reversal of its sign. To demonstrate the correctness of this assumption, the converter's output current was adjusted to $5 \mathrm{~A}$ and the power loss in the entire converter was determined for the first configuration of the inductor as well as for the third configuration, as the latter resulted in the biggest negative change in power dissipation for the initial output current of $3 \mathrm{~A}$ (see Table 3 ). The results of this analysis are given in Table 6. As shown, no increase in the converter's performance was registered. 
Table 6. Properties of inductors and corresponding change in total power loss for the output current of 5 A.

\begin{tabular}{|c|c|c|c|c|c|}
\hline \multicolumn{3}{|c|}{ Output Inductor - Properties } & \multicolumn{2}{c|}{ Change in Total Power Loss } \\
\hline Wire diameter mm & Wire material & $\begin{array}{c}\text { Total DC } \\
\text { Resistance } \boldsymbol{\Omega}\end{array}$ & $\begin{array}{c}\text { Inductance } \\
\mathbf{H}\end{array}$ & $\begin{array}{c}\text { Power Loss } \\
\text { W }\end{array}$ & $\begin{array}{c}\text { Change in } \\
\text { Dissipation W }\end{array}$ \\
\hline 0.71 & $\mathrm{Cu}$ & 0,041621 & 0,00003054 & 18,43654 & - \\
\hline $0.71 / 0.5 / 0.71$ & $\mathrm{Cu}$ & 0,054278 & 0,00003119 & 18,86280 & 0,426260 \\
\hline
\end{tabular}

\section{Conclusions}

The impact of the fringing field of the air gap on power loss and temperature distribution in the coil of gapped ferrite inductors can be reduced by modifications to the wire's diameter and material in sections of the coil exposed to the strong fringing field. It may at first seem counterintuitive that overall power loss can be lessened by reducing the diameter of the wire, since a reduction in diameter normally leads to an increase in resistance, and resistance causes power loss. However, in coils heavily impacted by the gap effect, a trade-off can be made between power loss caused by the useful current and power loss due to the fringing field, leading to a reduction in total power loss and more efficient designs.

\section{REFERENCES}

[1] Papastergiou K.D, Macpherson D.E.: Air-gap effects in inductive energy transfer, Power Electronics Specialists Conference, 2008. PESC 2008. IEEE, 4092-4097

[2] Ericson R.W., Maksimovic D.: Fundamentals of Power Electronics, Springer Science+Business Media, 2001, p506-522.

[3] Kasikowski R., Więcek B., Farrer M.: Thermographic measurement and thermal modelling of air gap inductors in H-F power forward converters. 13th Quantitative InfraRed Thermography Conference, qirt.2016.053.

[4] Dixon L.H.: Eddy Current Losses in Transformer Windings and Circuit Wiring. Texas Instruments Inc., 2003.

[5] Riba J.: Calculation of the ac to dc resistance ratio of conductive nonmagnetic straight conductors by applying FEM simulations. European Journal of Physics 2015.

[6] R. Kasikowski, B. Wiecek., Ascertainment of fringing-effect losses in ferrite inductors with an air gap by thermal compact modelling and thermographic measurements. Applied Thermal Engineering 124 (2017) 1447-1456.

[7] Ferroxcube Data Handbook: Soft Ferrites and Accessories, p.493, 2009. 